\title{
Preparing for an uncertain future with climate smart agriculture
}

by Karen Ross, Secretary, California Department of Food and Agriculture

C

alifornia is the nation's leading agricultural state, with 76,400 farms producing more than 400

The mission of the California Department of Food and Agriculture (CDFA) is to promote and protect agriculture. It's a complex job - and one that is getting more complex as the climate changes.

With the current drought in its fourth year, California has already started to experience some of

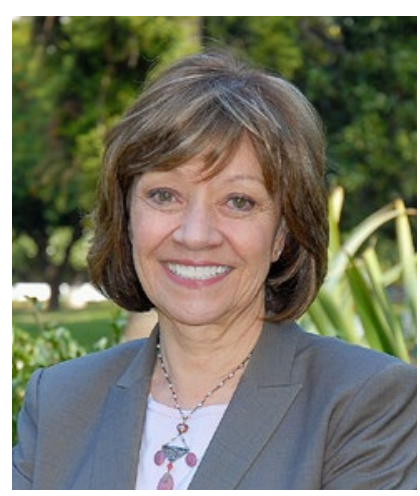
the anticipated impacts of climate change. With drought, we have seen economic losses including job losses, fallowed land, and greater demand for a limited amount of water. A concerted approach is urgently needed to prepare California agriculture for future climate change impacts. One essential approach is embracing and implementing the concept of climate smart agriculture.

Practicing climate smart agriculture means following three principles: developing agricultural systems that are resilient to climate change; reducing greenhouse gas emissions from agriculture; and preparing for climate change in a way that keeps farms productive and profitable.

I heard a lot about climate smart agriculture during a recent visit to the Netherlands with a delegation of agricultural leaders from California. The Netherlands is a leading agriculture distributor in Europe and the world's second largest (after the United States) agricultural exporter. Climate smart agriculture is already strongly integrated into Dutch economic and food security strategies. Our delegation not only heard about the threats from higher precipitation, but also about how overly dry conditions in the summer threaten the stability of peat dikes, which dry up to the point that they may simply float away, compromising the levee structure in a region where most of the land is below sea level.

In California we can prepare for such multi-faceted impacts through our own climate smart agriculture initiatives. At CDFA, we have a variety of programs and efforts underway to support agricultural

\footnotetext{
More-efficient irrigation technologies - like this drip system in an almond orchard in Yolo County — save water, conserve energy and reduce greenhouse gas emissions.
}

sustainability, build resilience to climate change and reduce greenhouse gas emissions:

The State Water Efficiency and Enhancement Program (SWEEP) is an emergency drought program implemented at the direction of Gov. Jerry Brown to assist farmers in moving to efficient water irrigation systems that save water, conserve energy and reduce greenhouse gas emissions. To date, SWEEP has funded 233 projects totaling almost $\$ 18$ million with $\$ 10.5$ million in matching grower funds. The program is built on a strong scientific foundation and supported by a collaborative partnership involving other agencies, resource conservation districts, the California State University (CSU) system and UC ANR Cooperative Extension (UCCE). The academic institutions play a key role in providing technical evaluations of applications for water savings and reductions in energy consumption.

The Dairy Digester Research and Development Program, launched in 2014, provides incentives for dairy operations to install manure digesters. Digesters capture methane from dairy lagoons, allowing the gas to be used to generate electricity. Methane is a shortlived climate pollutant that is 28 times more potent as a greenhouse gas than carbon dioxide. In 2015, CDFA awarded \$11.1 million for the development of five digesters at California dairies. Matching funds by developers totaling $\$ 19$ million were allocated to these projects. The digester program is supported by several scientific experts from the University of California as well as a technical advisory sub-committee. The program highlights the many opportunities to use agricultural byproducts for multiple benefits, including the generation of electricity.

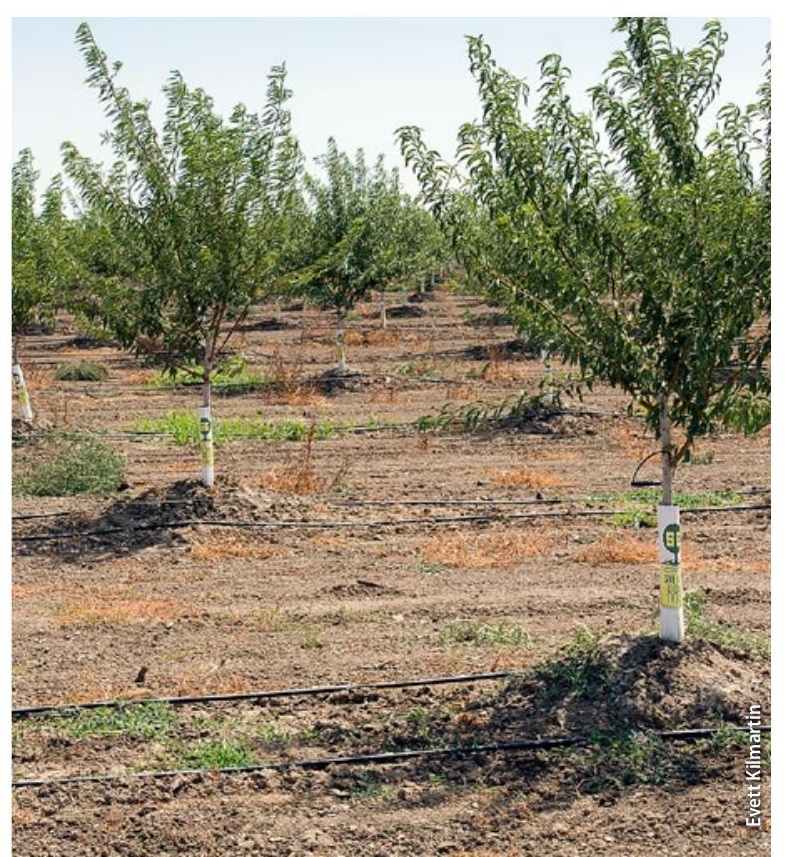




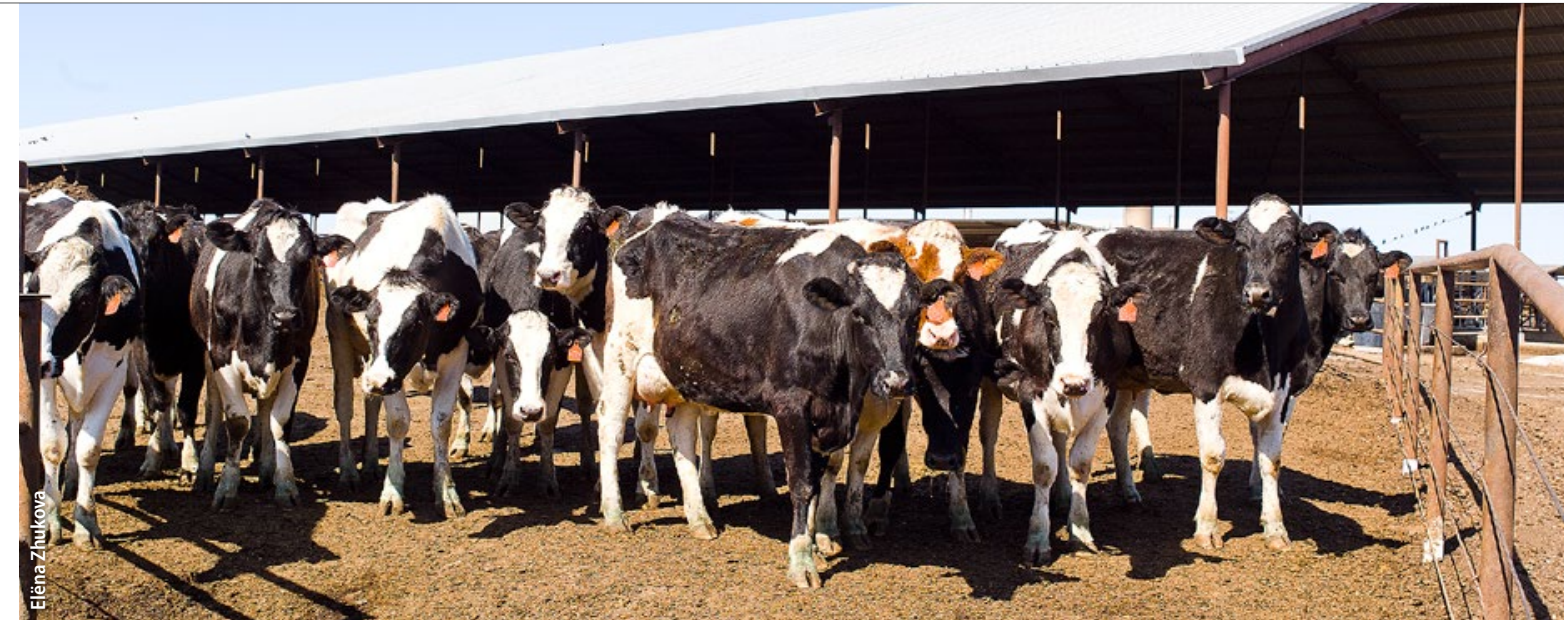

The Fertilizer Research and Education Program has a long-standing collaboration with UCCE to provide growers with cost-effective practices to improve the efficient use of fertilizer and minimize environmental impacts. Improving the timing and rate of nitrogen fertilizer application can help to prevent leaching and runoff as well as emissions of nitrous oxide $\left(\mathrm{N}_{2} \mathrm{O}\right)$, another potent greenhouse gas. Efficient use of fertilizer also reduces the amount applied, saving money for the grower.

Under the Healthy Soils Initiative, Gov. Brown has directed CDFA to lead an interagency collaboration to promote the development of healthy soils that sequester carbon on working lands. The health of agricultural soil influences its ability to build and retain adequate organic matter via the activity of plants and soil organisms. Adequate organic matter helps to enable the soil to function as a vital living ecosystem and provide the foundation for sustainable agricultural productivity. Carbon sequestration has been difficult to quantify in soils given the long time period for the accumulation of stable soil carbon pools. However, recent work by the Natural Resources Conservation Service (NRCS) has yielded results that allow for the scientific estimation of greenhouse gas reductions associated with several soil management practices (comet-planner.com/). These management practices can be implemented on a wide range of croplands and rangelands. We are eager to collaborate with UCCE, NRCS, resource conservation districts and other researchers to advance this important work as part of climate smart agriculture.

These are a few examples of practices that can reduce greenhouse gases and increase climate resilience on our farms and ranches. Gov. Brown's 2016-2017 proposed budget signals California's ongoing support for these initiatives, including \$20 million for SWEEP, \$35 million for the dairy digester program and $\$ 20$ million for the Healthy Soils Initiative. In addition, the proposed budget includes $\$ 40$ million for the Sustainable Agricultural Lands Conservation Program, overseen by the Strategic Growth Council (sgc.ca.gov/s_salcprogram.php) and administered by the Department of Conservation, and which supports the protection and sustainable management of California's agricultural lands through planning and conservation via agricultural easements.

Going forward, CDFA's climate smart agriculture initiatives will be coordinated through the newly created Office of Environmental Farming and Innovation (cdfa.ca.gov/EnvironmentalStewardship/).

There is no doubt we can do more in the climate smart agriculture arena. As we continue to expand our work in this area, CDFA will continue to work closely with our partners, including the scientific and technical experts at the CSU and UC systems. We are fortunate in California to have such expertise available to support our food production system with sound research, an extensive technical support infrastructure and an enormously accomplished agricultural extension service. CA

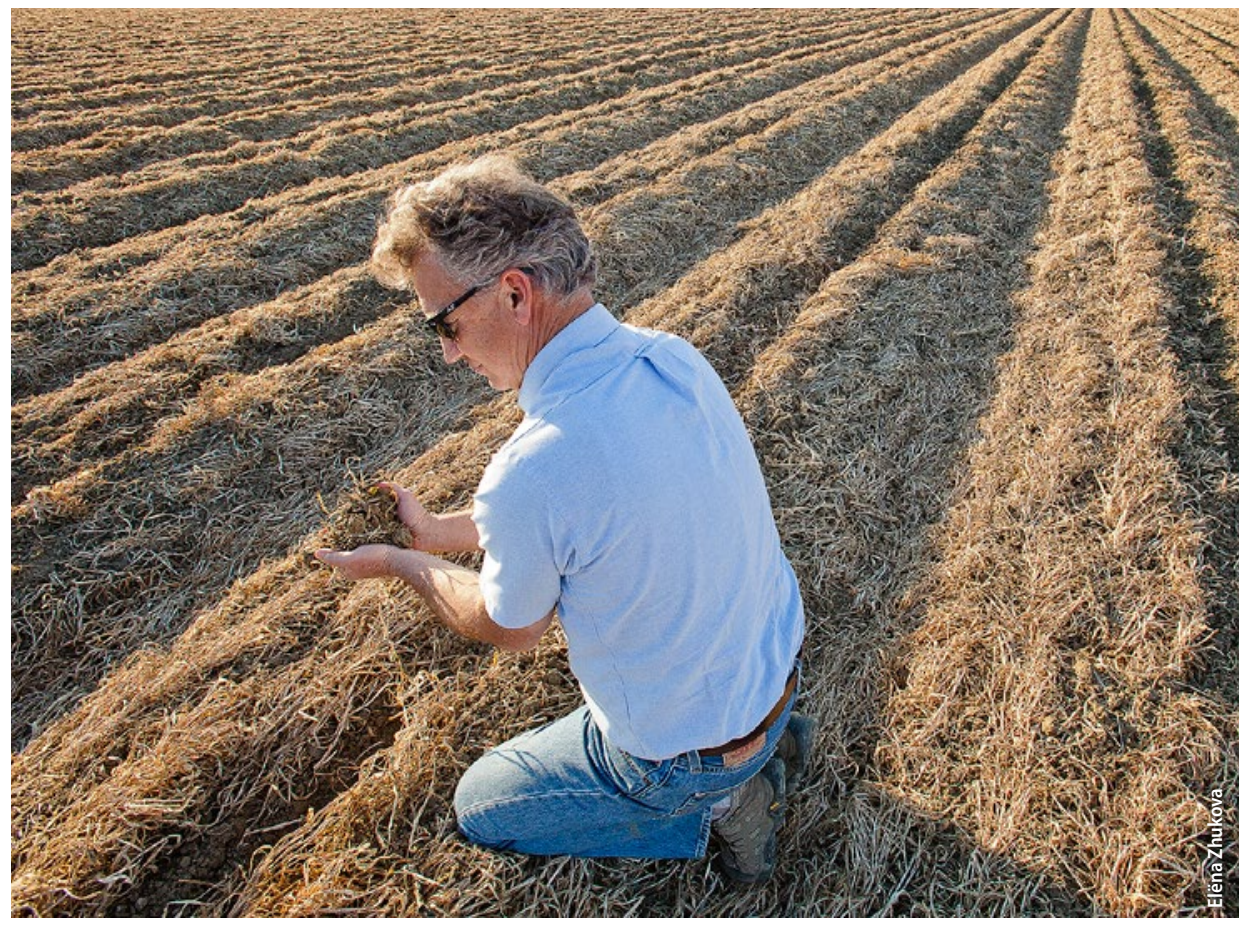

